\title{
A história oral como intercessor - em favor de uma dessujeição metodológica
}

\section{Oral History as an intercessor - dessujecting social researchers}

\section{Heliana de Barros Conde Rodrigues*}

Professora do Departamento de Psicologia Social e Institucional da Universidade do Estado do Rio de Janeiro - UERJ, Rio de Janeiro, RJ, Brasil

\begin{abstract}
Resumo
Recorrendo ao conceito deleuziano de intercessor, o artigo visa a por em cena certa prática da História Oral como dispositivo epistemológico-narrativo de invenção. Os problemas que assediam os oralistas se prendem, hoje, menos a demonstrações de que as fontes orais devam gozar do prestígio associado a procedimentos científicos do que a uma singularização da História Oral enquanto crítica em ato aos cânones hierarquizantes no campo da pesquisa social - âmbito em que as contribuições de Alessandro Portelli se mostram decisivas. O livro Changer de société. Refaire de la sociologie, de Bruno Latour, permite fabricar uma intercessão adicional, pois a análise latouriana potencializa as proposições de Portelli quanto à forma de representatividade imanente à História Oral e ao valor diferencial da relação entrevistador-entrevistado no que tange à reflexividade.
\end{abstract}

Palavras-chave: Representatividade, Reflexividade, Intercessor, História oral; Associologia.

\begin{abstract}
:
This paper, appealing to the concept of intercessor, aims to construct an Oral History as epistemological-narrative device of invention. Today the oralists don't need to demonstrate the cientificity of Oral History; they need to use Oral History as a critic of hierarchical forms of classifying knowledges, and the contributions of Alessandro Portelli are decisive in that scope. In addition, the Bruno Latour's book Changer de société. Refaire de la sociologie allows to create a new interception which potencializes Portelli's contributions in order to rethink representativeness and reflectivity in social research.
\end{abstract}

Keywords: Representativeness, Reflectivity, Intercessor, Oral history, Associology. 
Quanto valeria um pensamento que nunca fosse transformado por seu objeto?

Pierre Lévy

\section{I ntrodução: sujeição e subjetivação na arena dos métodos}

O presente artigo, cuja elaboração foi provocada pelo título do dossiê a que se destina - Produção de conhecimento e políticas de subjetivação -, liga-se de perto a minha experiência como orientadora de dissertações e teses em um curso de pós-graduação em Psicologia Social ${ }^{1}$. Nesse contexto, o "problema da metodologia" constitui uma espécie de penoso fantasma para os pós-graduandos. Estes anseiam por método, mas ao mesmo tempo, à primeira vista paradoxalmente, percebem as disciplinas de cunho declaradamente metodológico como tediosas, descontextuadas e, em última instância, inúteis para seus propósitos de pesquisa e escritura.

Não viso a "corrigir" essa apreensão com a oferta de alguma milagrosa panacéia. De tal providência, aliás, estão repletos certos cursos e manuais de metodologia que, justamente por propô-la, desencantam os pesquisadores. Junto a companheiros discursivos que põem em destaque as políticas de subjetivação - Deleuze, Guattari, Foucault, Lourau, Becker, entre outros -, há muito temos ressaltado que participamos da produção daquilo que supostamente apenas investigamos - o que não constitui uma falha a eliminar, mas uma problematização a ser acolhida, exposta e debatida naqueles momentos em que nos dispomos, vaidosos, ao que se denomina "produção de conhecimento".

$\mathrm{Na}$ qualidade de pesquisadores aos quais se encomenda algo dizerem acerca da subjetividade em suas conexões com o social, temos exercitado, conseqüentemente, um alegre cuidado: aquele que busca apreender, inclusive (ou em especial) na presumida assepsia dos métodos, o engendramento daquilo que, ao fazer-se assim "objeto", se vê sujeitado às ações de algum outro e/ou outrem racionalidades, disciplinas, comunidades acadêmicas etc.

Talvez isso não nos baste, contudo. Pois se decerto visamos à dessujeição de nossos pesquisados, não é menor a busca de análoga dessujeição quanto a nós mesmos, pesquisadores sociais. 0 contemporâneo nos oferece uma gama de procedimentos alegadamente favoráveis a ambos os intuitos: a pesquisa qualitativa, a pesquisa intervenção, a apreensão ou construção de analisadores, a atenção às diferenças de sentido, a idéia de construção social da realidade, a análise das instituições, a escrita diarística, a entrevista aberta, a análise de implicações, a imersão intensiva no campo de pesquisa etc. Embora todas essas estratégias possam favorecer, de uma forma ou de outra, a dessujeição de pesquisados e pesquisadores - só uma análise singularizada poderia avaliá-lo, a cada situação, de forma extra-normativa -, o presente artigo volta-se 
para minhas próprias aventuras nesse sentido, mediante a prática de certa História Oral.

Para tanto, o conceito deleuziano de intercessor servirá de reiterado mote. Passemos, portanto, a essa experimentação que, conquanto sem garantias, aspira a contribuir para um processo de dessujeição metodológica, ou seja, para uma interferência em algumas das "certezas investigantes" (eventualmente subjugadoras) dos pesquisadores sociais.

\section{I nterceptar, interceder, fazer rizoma: a erva em nós}

O termo intercessão tem sido eventualmente associado a seu homófono, relativo à interseção matemática, tendo por efeito aparentar o primeiro a sínteses, conciliações ou coincidências parciais entre conjuntos previamente delimitados e isolados. No entanto, se a algo se pode remeter o conceito de intercessor no sentido deleuziano, é ao verbo interceptar, com as conotações de deriva ou desvio que este último comporta; ou, alternativamente, ao verbo interceder, menos por suas conotações religiosas do que pela necessária função de correlação que ele sugere.

É freqüente que Deleuze, ao falar de intercessores, nos ofereça o já célebre exemplo da abelha e da orquídea, que se conectam em uma evolução a-paralela (DELEUZE; PARNET, 1980). Todavia, em função das características do presente artigo - voltado primordialmente a problematizar a posição asséptica do pesquisador -, optamos por recorrer a um momento no qual, sem lançar mão do termo em apreço, Deleuze (em intercessão, por sinal, com Guattari) o torna uma potente ferramenta na direção almejada. Neste sentido, apreciemos fragmentos de Rizoma:

O mimetismo é um conceito muito ruim, dependente de uma lógica binária, para fenômenos de natureza inteiramente diferente. [...] A Pantera Cor-de-rosa nada imita, nada reproduz; ela pinta o mundo com sua cor, rosa sobre rosa, é o seu devir-mundo, de forma a tornar-se ela mesma imperceptível [...]. Sabedoria das plantas: inclusive quando elas são de raízes, há sempre um fora onde elas fazem rizoma com algo [...]. "A embriaguez como irrupção triunfal da planta em nós". (DELEUZE; GUATTARI, 1995, p. 20)

Um pesquisador embriagado torna-se imperceptível, em lugar de transcendente-soberano; correlativamente, a planta já coloriu o mundo a pesquisar de sua cor. Deleuze e Guattari não receiam o estabelecimento de conexões com a literatura e/ou o cinema, sejam eles considerados nobres ou "de massa" (qual J orge Castañeda ou as famosas comédias de Peter Sellers, por exemplo); ao mesmo tempo, inclusive as ciências ditas "duras", quais as neurociências, podem tornar-se intercessoras - não por cânones de rigor aos quais 
deveríamos nos curvar, mas pelas eventuais linhas de fuga que cheguem a propiciar: "Muitas pessoas têm uma árvore plantada na cabeça, mas o próprio cérebro é muito mais uma erva do que uma árvore" (DELEUZE; GUATTARI, 1995, p. 25).

Nós, pesquisadores sociais - sociólogos, etnólogos, historiadores, psicólogos sociais -, temos inúmeras árvores plantadas na cabeça, por vezes a tal ponto imperativas que não mais nos embriagamos de planta ou erva - ou só o fazemos, seres binários, depois da ciência, do trabalho sério...

De minha parte, no entanto, a aproximação a certa História Oral favoreceu irrupções triunfais de alguns impensados.

\section{Potentes estranhamentos}

Por que não utiliza a História Oral? - disseram-me ao saber que iniciava uma investigação sobre a história recente das práticas 'psi' no Brasil. Relutei, de início. A presença de entrevistas em pesquisas eventualmente já me soara como "profecia auto-realizadora": as palavras dos narradores emergiam então na qualidade de mera confirmação das hipóteses do pesquisador ou, na pior das hipóteses, violentamente interpretadas segundo algum esquema teórico por ele postulado como uma obviedade.

Mas a curiosidade moveu-me em direção à História Oral. Admito que ali encontrei muito do que temia; descobri igualmente, porém, um intercessor apto a desenraizar obstáculos sujeitadores: o trabalho do oralista italiano Alessandro Portelli. Sendo assim, a seguir é apresentada não sua obra - tentativa que seria inglória -, mas algumas irrupções por ele propiciadas quanto a duas das consignas metodológicas que assediam os pesquisadores sociais: a exigência de representatividade dos pesquisados quanto a alguma espécie de grupo previamente postulado e o pressuposto da reflexividade como virtude exclusiva do pesquisador-entrevistador em seu contato com os narradores.

Acerquemo-nos da primeira através do artigo Philosophy and the facts. Subjectivity and narrative form in Autobiography and Oral History (PORTELLI, 1997a). À primeira vista, trata-se de um trabalho de cunho metodológico; porém esta dimensão jamais aparece, na pena de Portelli, na triste forma dos manuais "how to". Qual no tipo de história oral que ele pratica, em que se combinam/confrontam diferentes vozes, as questões de método se fazem e refazem à medida que caminha por estradas, livros, canções e narrativas².

Nosso próprio caminho convida a frisar que entre as peculiaridades dos relatos orais enfatizadas por Portelli encontra-se a parcialidade caráter que a põe em imediato confronto com a tão demandada representatividade. Pois sendo cada nova narrativa, segundo o oralista italiano, capaz de modificar significativamente as conclusões 
de uma investigação, não se correria o risco, ao adotar o procedimento, de menosprezar a busca por tendências ou regularidades, recaindo em um vulgar fascínio pela experiência individual? E não seria isto um imperdoável pecado tratando-se de ciência social, de história social, de psicologia social, implicando reverenciar um ídolo que deveria ser derrubado - o "psicológico" -, por mais que ele possa provir, como é freqüente em História Oral, dos outrora silenciados?

J ustamente da situação de um desses silenciados, Frederick Douglass - ex-escravo que se tornou eloqüente orador -, parte Portelli para pôr em análise o parâmetro representatividade. Embora os abolicionistas brancos recomendassem a Douglass que se limitasse a relatar 'fatos', deixando as interpretações (ditas 'filosofia') a cargo de homens mais preparados, sua autobiografia ${ }^{3}$ está repleta de juízos pessoais. Douglass compara, por exemplo, dois feitores, Mr. Severe e Mr. Hopkins: o primeiro "parecia ter prazer" em atormentar os escravos, enquanto o último "era um homem muito diferente", que "açoitava, mas não parecia obter prazer com isso" (DOUGLASS apud PORTELLI, 1997a, p. 80).

Portelli chama atenção para o fato de que Douglass perceba como importante aquilo que Mr. Hopkins sentia; melhor dizendo, aquilo que ele sentia que Mr. Hopkins sentia. Em seguida, qual faria um oponente, indaga: que diferença os sentimentos dos feitores podem fazer para os escravos, já que eram chicoteados de qualquer modo? Sua resposta se ancora, primeiramente, nos juízos do próprio Douglass:

\begin{abstract}
Os golpes do açoite deixam uma marca no corpo do escravo de acordo com a força física com que são desfechados; mas deixam também uma marca na alma de acordo com o estado de espírito que transmitem. A relutância de Mr. Hopkins [...] tornou-se, para o jovem Frederick Douglass, um sinal da contradição entre a escravidão e a natureza humana [...]. (PORTELLI, 1997a, p. 80)
\end{abstract}

Na seqüência da argumentação, o oralista italiano volta a agir qual advogado do diabo, desafiando: como podemos saber o que Mr. Hopkins realmente sentia? Sendo a experiência de Douglass individual e idiossincrática, o que nos autoriza a crer que tenha algum valor para a pesquisa de cunho social?

Atenhamo-nos a esse problema da representatividade - árvore que temos plantada na cabeça? - , acompanhando a trilha de Portelli. Este logo nos leva a conhecer o trabalho dos historiadores quantitativos ("cliometras") Robert Fogel e Stanley D. Engerman, intitulado Time on the cross: the economics of American negro slavery (1974). Nada preocupados com sentimentos ou interpretações, esses autores norte-americanos dedicam-se a computar, com apoio em extensas 
fontes documentais e sofisticadas análises estatísticas, o número de surras aplicadas aos escravos. Chegam à conclusão de que é provável que um escravo fosse açoitado uma média de 0,7 vezes ao ano.

Portelli não desqualifica a capacidade de abstração dos leitores com a alegação de que tal número de surras seria impossível de aplicar argumento tolo que só a todos contenta; as desventuras da história quantitativa são estabelecidas através de análise bem mais produtiva.

O trabalho de Fogel e Engerman teve grande repercussão nos círculos intelectuais e políticos dos Estados Unidos ao supostamente demonstrar que, sendo os escravos espancados com pouca freqüência, as chibatadas não fariam grande diferença em suas condições de existência. Podendo-se dizer negligenciável, em termos estatísticos, o intervalo entre 0,7 e zero, concluir-se-ia pela inexistência de diversidade considerável entre a escravidão e outras condições de exploração (operária, por exemplo). A fim de refutar este argumento e, particularmente, de teorizar acerca da singular representatividade dos relatos orais, basta-nos parte de um parágrafo de Portelli (1997a):

A diferença entre trabalhadores livres e escravos não está em quantas vezes os últimos são chicoteados, mas no fato de que escravos podem ser chicoteados e trabalhadores livres, não. [...] Se noventa e nove escravos nunca são tocados e um recebe setenta surras, a experiência "excepcional" do último determina o comportamento ordinário de todos os outros, porque representa a possível sina de todos, cujo comportamento visará a evitá-la. (p. 87)

O argumento abre conexões com o conceito de virtual, conforme pensado por G. Deleuze - algo real, por mais que não atualizado em estados de coisas -, bem como com escolas historiográficas que enfatizam o valor daquilo que é aparentemente excepcional como recurso para dar conta do habitual - caso da micro-história italiana. Em nítida relação com esses temas, adenda Portelli:

A história oral oferece menos uma grade de experiênciaspadrão do que um horizonte de possibilidades compartilhadas, reais ou imaginadas. O fato de que essas possibilidades raramente estejam organizadas em [...] padrões coerentes indica que cada pessoa entretém, a cada momento, múltiplos destinos possíveis, percebe diferentes possibilidades e faz escolhas diferentes de outras na mesma situação. Esta miríade de diferenças individuais [...] serve para lembrar que, além da necessária abstração da grade das ciências sociais, o mundo real é mais semelhante a um mosaico ou patchwork de diferentes pedaços, que se tocam, superpõem e convergem, mas igualmente acalentam uma irredutível individualidade. (PORTELLI, 1997a, p. 88) 
Embora o autor preze o termo individualidade - passível de encaminhar a novos aprisionamentos (grades de experiênciaspadrão?) -, há que saber distinguir palavras e conceitos: Portelli não nos dirige ao triste sujeito psicológico, interiorizado e auto-centrado, mas a um mundo em que nada é o "uno", ou o "o", porque se compõe à moda do mosaico ou da costura de inelimináveis diferenças, nada harmônicas e jamais totalmente pré-fixadas. Há, é claro, diagramas que incidem nas pedras do mosaico ou retalhos do patchwork no sentido de estabilizá-los; mas tais diagramas tampouco totalizam "um" ou "o" real social. São somente "do" real, por mais que cheguem eventualmente a obter convergências de tal monta que nos sintamos tentados a reduzir as diferenças a meros avatares de uma Grande Narrativa (de chicotadas médias, para aproveitar o exemplo...).

A fim de que nos habilitemos a preservar uma desejável dispersão, cumpre, ao ver de Portelli, deixar-se interceptar pela oralidade, pois ela lida "com porções do mosaico que não podem ser subsumidas pela grade" e nos surpreende com elementos que, embora eventualmente fragmentários e difíceis de narrar, parecem ser "mais consistentes não só com a presença da subjetividade, mas igualmente com a objetiva realidade das coisas" (PORTELLI, 1997a, p. 88).

Presença da subjetividade e objetiva realidade das coisas: haverá como separá-las? Evidentemente sim, em perspectivas que defendem mandatos disciplinares, respectivamente psicologistas e sociologistas. Lamentavelmente sim, naquelas outras que se esforçam por reuni-las - linear ou dialeticamente -, depois de as haver separado, fazendo com que carreguem, para o encontro e/ou confronto, toda a sua carga de transcendência. Definitiva e desejavelmente não, quando, preservando-se a imanência, o real é divisado como algo mais complexo do que aquilo que se encontra atualizado, comportando as virtualidades e devires que a pesquisa social hegemonicamente praticada entende tão mal. Sendo assim, para pesquisadores que não sejam vulgares representantes de ofícios-corporações, a representatividade se faz patente, em História Oral, justamente por estar em linha de fuga quanto a serialidades... escravizadoras.

Com estas conclusões parciais em mente, passemos a um segundo aspecto da modalidade de História Oral praticada por Portelli, em que são postas em pauta as relações entre o entrevistador e os narradores. Quanto a esse problema, por sinal, é possível esquematizar, com algum humor, uma mudança de perspectiva por parte do meio acadêmico, na virada dos anos 1970 para os 1980, acerca dos historiadores orais: antes ridicularizados como um grupo de tolos que acredita em vidas-histórias insignificantes, esses 
historiadores passam a ser vistos como um grupo de espertos capaz de dar conta, via história da memória, daquilo que tolos insignificantes pensam ser verdadeiro. Tal modificação costuma ser atribuída à presença da reflexividade do persquisador: virtude exclusiva deste último, ela estaria ausente no narrador, presumidamente movido, quanto à própria memória, por dimensões ou forças que ignoraria.

O trabalho de Portelli intitulado Oral history as genre, ao qual passamos a recorrer, contém uma via alternativa a essa empedernida díade. Ali, o autor enfatiza que na história oral renovada pelas posturas críticas não está em pauta a passagem de uma crença cega a um descrédito iluminista - onde um dos pólos, historiador ou narrador, aparece como o bobo da história -, mas a percepção de que "a história oral é um discurso dialógico, criado tanto pelo que os entrevistados dizem quanto pelo que os historiadores fazem - pela presença dos historiadores no campo e pela apresentação do material pelos historiadores" (PORTELLI, 1997b, p.3).

Para elucidar tal perspectiva, Portelli percorre variados aspectos da relação dialógica e da composição narrativa. Cumpre destacar, quanto ao que nos interessa mais de perto, a especificidade do que é dito em uma entrevista: trata-se de um tempo crítico em que uma história de vida é explicitamente demandada - história de vida esta que, provavelmente, nunca fora explicitada antes da mesma forma, pois relatos pessoais ou familiares em geral emergem, na vida cotidiana, sob a forma de fragmentos, repetições, mexericos, e não como narrativa coerente e organizada. Ainda nesse sentido, Portelli nos lembra que a iniciativa da entrevista parte do entrevistador: o relato do entrevistado é uma resposta à questão inicial e não, como na autobiografia clássica, uma decisão tomada pelo narrador (nunca isenta de demandas, é certo, porém diversas daquelas presentes no dispositivo da história oral, que implica formas de aproximação, negociações, conflitos eventuais etc.).

Os tópicos apresentados no parágrafo anterior revestem-se de suma importância quando se concebe a história oral como um "gênero de discurso em que a oralidade e a escritura se desenvolvem em conjunto a fim de falar uma com a outra sobre o passado" (PORTELLI, 1997b, p. 5). Quanto a esse gênero de investigação e discurso, contudo, Portelli privilegia o problema da reflexividade ao indagar: quem fala com quem em história oral? Em sua perspectiva, nem um esperto a um tolo nem o oposto, mas alguém ( 0 pesquisador) que tem um plano de investigação e indagações transformáveis - via conflitos, alianças e negociações - com alguém (o narrador) que tem expectativas, fantasias e reações ao proposto pelo primeiro. 
Este tipo de situação é temido por muitos cientistas sociais. Diz-nos Portelli que Franz Boas costumava advertir seus alunos quanto aos riscos representados pelos "índios inteligentes", que poderiam "ter formado uma teoria" sobre a pesquisa em andamento. Margaret Mead, por seu turno, emitia avaliações críticas acerca dos pesquisadores ativos: "O trabalhador de campo não está ali para falar, mas para escutar", nunca devendo "exprimir idéias complicadas de sua própria autoria, que embaralham os relatos dos nativos" (PORTELLI, 1997b, p. 11).

Analisando tais recomendações metodológicas, Portelli entrevê a indesejável presença de uma simetria medrosa, a qual engendra uma separação hierárquica entre as idéias do entrevistador e o relato do entrevistado. Com base em uma ficção de não- interferência aspirase a transformar o que seria diálogo em dois monólogos: "o informante oferece um monólogo de fatos brutos, enquanto historiadores ou antropólogos fornecem - mais tarde, na segurança de seus gabinetes - um monólogo de idéias sofisticadas das quais os informantes nunca ouvem falar (PORTELLI, 1997b, p. 12).

Há, pois, dois estereótipos em cena: o do "nativo bobo" - que falaria sem ter qualquer idéia (que dirá teoria reflexiva!) acerca daquilo que fala, daquele a quem fala e da razão por que fala; e outro, mais surpreendente - já que o anterior povoa o imaginário hegemônico da formação de pesquisadores -, o do "filósofo bobo", que apareceria, aos olhos do "nativo", como uma tabula rasa teórica, política e existencial.

Dois exemplos trazidos por Portelli desconstroem esse binarismo restritivo: um estudante romano reverte o fluxo entrevistadorentrevistado, retrucando, ao professor que lhe solicita um relato de vida, com perguntas sobre a vida do próprio professor; um cantor popular das proximidades de Roma em certo momento revela que formara uma opinião acerca do historiador que Ihe solicitava uma entrevista (e, conseqüentemente, se deveria concedê-la, de que modo etc.) ao observar o tipo de jornal que este carregava no banco traseiro do carro.

Nossos pesquisados não são bobos. E não o são, em especial, quando não nos vêem, nem a si próprios, como tal - a ponto de, eventualmente,.. até se fazerem de bobos. Essas peculiaridades da relação entrevistador-entrevistado levam Portelli a uma acurada conclusão relativa a nossa orgulhosa, e pretensamente exclusiva, reflexividade:

Quanto menos os historiadores revelam sobre sua identidade e seus pensamentos, maior a probabilidade de que os informantes expressem seu testemunho nos termos mais amplos e seguros, limitando-se às camadas mais superficiais 
de sua consciência e aos aspectos mais públicos e oficiais de sua cultura. (PORTELLI, 1997b, p. 12)

\section{As coisas estão no mundo, só que eu preciso aprender}

A despeito de havermos utilizado o termo no singular, para Deleuze os intercessores são sempre múltiplos: somente o plural provoca o pensamento. Logo, não há de surpreender que após apelar à História Oral (à moda Portelli) em busca de elementos de dessujeição de nosso "pensar metodológico", forçando-o a sair de sua imobilidade, algo mais interceda ou intercepte. Intensamente transformadas no contato com Portelli, as noções de representatividade e reflexividade, em nosso percurso, sofreram novas torções quando do encontro com o livro Changer de société. Refaire de la sociologie, de Bruno Latour, no qual o autor caracteriza sua perspectiva no campo dos Science Studies: a Actor-Network Theory (ANT) (LATOUR, 2006).

A sigla é sugestiva: ANT - formiga, em inglês. Ela de pronto faz evocar uma observação de Deleuze e Guattari: “É impossível exterminar as formigas, porque elas formam um rizoma animal do qual a maior parte pode ser destruída sem que ele deixe de se reconstruir" (DELEUZE; GUATTARI, 1995, p.18). Qual o que ocorre quanto a Portelli, qualquer tentativa de abordar a obra de Latour seria como defrontar-se com a multiplicidade de um formigueiro: constitui tarefa impossível em face de um pesquisador híbrido que mescla, sem receios, filosofia, sociologia, antropologia, política, estudos sociotécnicos, estudos ambientais etc.

No livro acima mencionado, Latour nos fala do uso, em diversos campos de pesquisa, do termo "social". Quanto ao manejo do mesmo, formula uma distinção entre o que chama de "Social número 1" ou "Sociologia do Social", devedor da tradição durkheimiana; e o que denomina "Social número 2", "Sociologia das Associações" ou "Associologia", que retoma aquilo que não se tornou grande na pesquisa social, ou seja, as propostas de Gabriel Tarde.

O autor se detém longamente em reflexões sobre os efeitos do pensar de uma, ou de outra maneira. Aqui, limitar-nos-emos a dois momentos dessa trajetória. O primeiro remete aos grupos - classes, categorias profissionais, estratos sócio-econômicos etc. - de que o pesquisador social costuma valer-se para classificar seus pesquisados, aspirando a que deles sejam "representativos". Nas palavras de Latour, que se faz decididamente tributário da posição tardiana,

enquanto a primeira abordagem permitia explicar cada atividade - o direito, a ciência, a tecnologia, a religião, as organizações etc. - reportando-se aos mesmos agregados 
sociais que operariam por trás delas, não existe, para a sociologia segunda versão, nada por trás dessas atividades, embora elas possam ser ligadas de uma forma que produz ou não chega a produzir - uma sociedade. Com efeito, tal é o ponto de divergência entre essas duas interpretações da sociologia: ser social não designa mais uma propriedade assegurada porque se trata de um movimento que tanto pode malograr ao estabelecer novas conexões como produzir um conjunto [assemblage] bem formado. (LATOUR, 2006, p. 16-17)

Prosseguindo nessa linha imanentista de pensamento, Latour sugere que questionemos as perspectivas hegemônicas ("Social número 1") e consideremos a natureza dos grupos ou agrupamentos como uma das controvérsias (incertezas) maiores das ciências sociais. A respeito, agrega:

Para os sociólogos do social, a ordem constitui a regra, enquanto o declínio, a mudança ou a criação são a exceção. Para os sociólogos das associações, a inovação é a regra e o que se trata de explicar - as exceções que dão a pensar são as diversas formas de estabilidade a longo termo e em grande escala. (LATOUR, 2006, p. 53)

O segundo momento a ressaltar diz respeito à análise do modo como o cientista vê, ouve e finalmente escreve acerca do que seus "objetos" Ihe oferecem no campo de pesquisa. Em coerência com a preservação das controvérsias ou incertezas, Latour deseja emancipá-los do papel de meros "informantes":

Com muita freqüência, os sociólogos - em particular os sociólogos críticos - se comportam como se eles fossem observadores "reflexivos" e "distanciados", confrontados a atores "ingênuos", "não críticos" e "não reflexivos". De fato, na maior parte do tempo, o observador se contenta em traduzir preguiçosamente as numerosas expressões de seus informantes no vocabulário das forças sociais ao qual está habituado. Sob o pretexto de fazer trabalho científico, o pesquisador se limitará a reafirmar aquilo de que o mundo social é feito; enquanto isso, os atores se contentarão em ser indiferentes às análise feitas sobre eles. Sem vergonha, os sociólogos tirarão de tal indiferença a conclusão de que os atores são cegos quanto ao que os determina. (LATOUR, 2006, p. 82)

Aproximando-nos do final do presente artigo, cumpre assinalar o valor que as considerações precedentes, oriundas de um autor dedicado aos Science Studies, possuem quer para os praticantes de História Oral, quer para os pesquisadores sociais em geral. Em Changer de société. Refaire de la sociologie, Latour nos lembra que, ao serem tomados como "objetos" pelos sociólogos da ciência, os 
cientistas imediatamente reagiram. Com isso, não pretende situar as ciências em um lugar especial: as ciências são práticas como as demais - não idênticas, porém tampouco superiores às demais. $O$ valor da observação reside em nos fazer ver que outros "informantes", que já resistiam a serem acriticamente explicados pela "sociologia do social" ("Social número 1"), não eram ouvidos, pois seu estatuto - o do homem comum, supostamente não reflexivo - os tornava, aos olhos dos pesquisadores, "menos gritantes" (LATOUR, 2006, p. 145) que os cientistas,... seus pares!

\section{Considerações finais: o valor da (in) disciplina}

A última observação de Latour nos conduz, qual em um túnel do tempo, a uma antiga declaração de Portelli. Em resposta ao publicado em 1978 no jornal La Repubblica, que acusava a História Oral de pressupor que "as coisas falam por si mesmas" - prescindindo, portanto, do árduo labor acadêmico (representativo e reflexivo?) -, retrucava ele então: “Não são coisas, mas pessoas (por mais que se trate de pessoas freqüentemente consideradas como meras coisas) que a história oral espera que se movam e falem por si próprias" (PORTELLI, 1998, p. 64) ${ }^{4}$.

Já Waddy Moore, presidente da Oral History Association, escreveu, também em 1978, irônicas observações sobre a presumida falta de treinamento metodológico dos oralistas: "Arranhe um historiador oral e haverá igual probabilidade de encontrar um folclorista, um sociólogo, um economista, alguém do campo das comunicações, da medicina, do governo, dos negócios, da literatura, do entretenimento e assim segue a lista" (MOORE apud PORTELLI, 1991, p. XI). Invariavelmente disposto a acolher ressalvas para mutá-las em positividades, Portelli virá a reconhecer, tempos depois, que Moore estava absolutamente certo: "ele estava de fato listando algumas das coisas que um historiador oral precisa ser a fim de tornar-se bom nesta tarefa" (PORTELLI, 1991, p. XI).

Pesquisados não são coisas, isto é, não constituem simples representantes de agregados ou forças sociais que apenas nós, pesquisadores, saberíamos apreender reflexivamente. Pesquisadores, por sua vez, não estão obrigados a se submeter (nem a subjugar os pesquisados) às invectivas corporativo-disciplinares que fundam (e mantêm) a ordem do discurso das arbitrárias partições acadêmicas.

O valor (e vigor) dessa(s) indisciplina(s) de parte a parte (pesquisados e pesquisadores) reside em propiciar uma experimentação criadora no campo da produção de conhecimento, que se faz visível e enunciável como uma política facultativa de subjetivação (versus sujeição). Nos termos de Deleuze - a quem tantas vezes fizemos menção ao longo do escrito que ora se encerra -, essa experimentação combate sem tréguas a "besteira" (bêtise). 
Pois esta não é o erro, a ilusão ou a ideologia, mas aquilo que restringe as conexões, os devires, ao apoiar-se em uma imagem dogmática do pensamento: "se as opressões são tão terríveis, é porque impedem o movimento, e não porque ofendem o eterno" (DELEUZE, 1992, p. 152).

Neste sentido, julgamos que a tarefa dos oralistas, hoje, prende-se menos a demonstrações de que o uso de fontes orais deva gozar do prestígio associado aos métodos científicos do que à possibilidade de fazer da História Oral uma crítica em ato aos cânones hierarquizantes no campo da pesquisa social. Pois "às ficções pré-estabelecidas que remetem sempre ao discurso do colonizador, trata-se de opor o discurso de minoria, que se faz com intercessores" (DELEUZE, 1992, p. 157).

Nosso artigo deixou-se embriagar por dois deles, nominalisticamente sintetizáveis como "Portelli" e "Latour". E faz votos, à maneira de um "caça fantasmas metodológicos", que se multipliquem.

\section{Referências Bibliográficas}

DELEUZE, G. Os intercessores. In: Janeiro: 34 Letras, 1992, p.151-168.

. Conversações. Rio de DELEUZE, G.; GUATTARI, F. Rizoma. In: Mil platôs v. 1. Rio de Janeiro: Editora 34, 1995, p.11-37.

DELEUZE, G.; PARNET, C. Diálogos. Valencia: Pré-textos, 1980. LATOUR, B. Changer de société. Refaire de la Sociologie. Paris: La Découverte, 2006.

FOGEL, Robert William; ENGERMAN, Stanley D. Time on the cross: the economics of American negro slavery. v.1. Boston and Toronto: Little, Brown, 1974.

PORTELLI, A. Introduction. In: The death of Luigi Trastulli and other stories: form and meaning in oral history. Albany: State University of New York Press, 1991, p. VII-XVI.

Philosophy and the facts. Subjectivity and narrative form in autobiography and oral history. In: _-_. The battle of Valle Giulia: oral history and the art of dialogue. Madison: University of Wisconsin Press, 1997a, p. 79-88.

Oral history as genre. In: . The battle of Valle Giulia: oral history and the art of dialogue. Madison: University of Wisconsin Press, 1997b, p.3-23.

What makes oral history different. In: PERKS, R.; THOMSON, A. (Eds.) The oral history reader. London and New York: Routledge, 1998, p. 63-74.

RODRIGUES, H.B.C. Alucinando Portelli. Celebração do amor entre um historiador (oral) e seu leitor. Mnemosine, v. 1, n.1, 2005. 
Disponível em: <http://www.mnemosine.cjb.net>. Acesso em: jul. 2009.

\section{Endereço para correspondência}

Heliana de Barros Conde Rodrigues

Universidade do Estado do Rio de Janeiro - UERJ, Rua São Francisco Xavier, 524, Bloco F, 10 andar, Instituto de Psicologia, CEP 20550-013, Rio de Janeiro-RJ ,Brasil

Endereço eletrônico: helianaconde@uol.com.br

Recebido em: 14/08/2009

Aceito para publicação em: 03/09/2009

Acompanhamento do processo editorial: Deise Mancebo, Marisa Lopes da Rocha, Roberta Romagnoli.

\section{Notas:}

* Doutora em Psicologia Escolar e do Desenvolvimento Humano pelo Instituto de Psicologia da USP.

${ }^{1}$ Programa de Pós Graduação em Psicologia Social da Universidade do Estado do Rio de Janeiro - UERJ, no qual ingressei em 2004.

${ }^{2}$ Uma tentativa de caracterizar a trajetória de Alessandro Portelli, explicitando suas conexões com a música, a literatura e a política, pode ser vista em Rodrigues (2005).

${ }^{3}$ Douglass, F. The life and times of Frederick Douglass (1892), republicado em 1962 (New York: Collier).

${ }^{4} \mathrm{O}$ artigo de Portelli do qual consta essa observação foi originalmente publicado em 1979 (em italiano) e 1981 (em inglês). 